3-3-2019

\title{
Race/ethnicity, citizenship status, and crime examined through trauma experiences among young adults in the United States
}

\author{
Chistopher A. Mallett \\ Cleveland State University \\ Miyuki F. Tedor \\ Cleveland State University, m.fukushima@csuohio.edu \\ Linda M. Quinn \\ Cleveland State University
}

Follow this and additional works at: https://engagedscholarship.csuohio.edu/clcas_facpub

Part of the Gender and Sexuality Commons, Race and Ethnicity Commons, and the Social Control, Law, Crime, and Deviance Commons

How does access to this work benefit you? Let us know!

\section{Publisher's Statement}

This is an Accepted Manuscript of an article published by Taylor \& Francis in the Journal of Ethnicity in Criminal Justice on March 3rd, 2019, available online: https://www.tandfonline.com/ doi/10.1080/15377938.2019.1570413.

\section{Recommended Citation}

Mallett, Chistopher A.; Tedor, Miyuki F.; and Quinn, Linda M., "Race/ethnicity, citizenship status, and crime examined through trauma experiences among young adults in the United States" (2019). Criminology, Anthropology, \& Sociology Faculty Publications. 7. https://engagedscholarship.csuohio.edu/clcas_facpub/7

This Article is brought to you for free and open access by the Criminology, Anthropology, \& Sociology Department at EngagedScholarship@CSU. It has been accepted for inclusion in Criminology, Anthropology, \& Sociology Faculty Publications by an authorized administrator of EngagedScholarship@CSU. For more information, please contact library.es@csuohio.edu. 


\title{
Race/ethnicity, citizenship status, and crime examined through trauma experiences among young adults in the United States
}

\author{
Christopher Allen Mallett ${ }^{\mathrm{a}}$, Miyuki Fukushima Tedor ${ }^{\mathrm{b}}$, and Linda M. Quinn ${ }^{\mathrm{c}}$ \\ ${ }^{a}$ School of Social Work, Cleveland State University, Cleveland, Ohio; 'Department of Criminology, \\ Anthropology, and Sociology, Cleveland State University, Cleveland, Ohio; 'Department of \\ Mathematics, Cleveland State University, Cleveland, Ohio
}

\begin{abstract}
Race/ethnicity, citizenship status, and trauma, have significant impact on delinquency and crime outcomes; though the reasons for some expected and unexpected crime pathways are still unanswered. Using data from the National Longitudinal Survey of Youth $1997(n=7,103)$, this study found the following results: no difference in the likelihood of engagement in delinquency and crime between blacks and whites; cumulative trauma increased delinquency and crime rates for all racial and ethnic groups; racial and ethnic minority groups compared to whites reported a significantly higher level of childhood trauma experiences; and native-born female immigrant groups (but not male) were more likely to engage in delinquency and crime than first-generation female immigrant groups. Implications and recommendations are set forth.
\end{abstract}

\section{ARTICLE HISTORY}

Received 28 June 2018

Revised 10 January 2019

Accepted 11 January 2019

\section{KEYWORDS}

Ethnicity; gender;

quantitative research; race

\section{Introduction}

Decades of empirical studies have identified multitude of risk factors for delinquency and crime engagement, including weak social ties, poverty, behavioral and mental health problems, drug and alcohol use, and poor parent-child relationship, among others, that could help explain crime engagement among adolescents and young adults (Hawkens, et al., 2000). One such risk factor, childhood trauma, encompasses many similar and divergent experiences of young people, such as maltreatment by family members, bullying, poverty, and neighborhood crimes. Many of these traumatic experiences, especially when experienced during childhood, are identified as serious risk factors for delinquency and young adult criminal activity (Yun, Ball, \& Lim, 2011).

A risk factor, like trauma, does not portend definitive delinquent or criminal outcomes, for criminal pathways can be diverted or minimized 
through a variety of approaches, such as improved family support, educational success, positive peer influences, trauma treatment, and other programing options that are available for young people and their families. These factors are referred to as delinquency and criminal protective factors, in contrast to delinquency and criminal risk factors like trauma (Howell, 2009). While not well investigated to date, it has been found consistently that immigrant (citizenship) status, especially first-generation immigration status, might be protective for adolescents and young adults becoming involved in delinquency or continuing criminal activity into adulthood (Bui, 2011; Kubrin \& Desmond, 2015).

Research continues to find that first-generation immigrants are less likely than those who are native-born to engage in crime in the United States. This is especially pertinent because this country is one of the most diverse populations in the world and its immigrant population has increased by nearly $24 \%$ since 2005 , making one out of every four young person either an immigrant or a child of immigrants (The Annie E. Casey Foundation, 2014). Indeed, though most empirical data suggest otherwise, one of the controversial immigration issues today is a common belief that immigrants, and in particular Hispanics, are prone to commit crimes at high rates. This is also of concern because Hispanics, and more specifically Mexicans, comprise the largest proportion of foreign born in the United States (Pew Research Center, 2017).

On the other hand, race/ethnicity minority status is often considered a serious risk factor for negative life outcomes in the United States, including involvement in juvenile and criminal justice systems, though the race/ethnicity difference in the actual engagement in delinquency is relatively small (Hockenberry, \& Puzzanchera, 2014). Because racial and ethnic minorities comprise a large proportion among the immigrant population in the United States, this study examines data from the National Longitudinal Survey of Youth 1997 (NLSY97) on how these opposing factors, race/ethnicity as a risk factor and citizenship status as a protective factor, relate to the engagement in delinquency and crime. Moreover, these relationships are examined through a risk factor for delinquency and crime, childhood and adolescent trauma experiences, which are expected to be higher among racial/ethnic minorities and those who are not born in the United States.

\section{Trauma as a risk factor for delinquency and crime}

Children and young adults experience trauma within three major domains: families, communities, and schools. Examples of childhood-specific traumas include maltreatment by parents, experiencing homelessness and other problems associated with financial difficulties, incarceration of family 
members, death of family members, living in unsafe or violent neighborhoods, witnessing violence in the neighborhood, bullying, and school difficulties. Though they do not necessarily occur together, young people who grow up poor are more likely to experience problems across all three domains through poor neighborhoods with higher crime rates and lowerquality schools. These trauma experiences, while not exhaustive of traumas studied in the literature, have been found to be serious risks for delinquency, offending behaviors, and young adult criminal activity (Child Trends, 2015; Currie \& Tekin, 2006; Kowalski \& Limber, 2013; Ryan, Herz, Hernandez, \& Marshall, 2007).

\section{Race/Ethnicity disparities in trauma}

In addition to the race/ethnicity-specific trauma related to discrimination (Kang \& Burton, 2014), research consistently indicates that children of color, especially black, Hispanic, and Native American children, are more likely than white children to experience trauma overall (Children's Defense Fund, 2014). The high likelihood of experiencing childhood trauma, along with being disproportionally impacted by low socio-economic status, might explain the racial and ethnicity gap across negative life outcomes, including delinquency and crime engagement especially across more serious offenders (The Sentencing Project, 2016).

\section{Poverty}

More than one in five children in the United States grow up in poverty, and those who grow up in poverty are, both minority and white, less likely to graduate from high school, and more likely to be poor as adults (Holzer, Schanzenbach, Duncan, \& Ludwig, 2007). Children of color are disproportionately more likely to grow up poor, with the youngest children most at risk, and nearly one in three children of color was poor in 2013. Of children of color, black children were the poorest (40\%), followed by American Indian/Native Alaskan children (37\%), and Hispanic children (34\%). More than two-thirds of these minority children who are born into poverty (for a family of four, the poverty guideline in 2018 was $\$ 25,100^{1}$ ) will be persistently poor for at least half of their childhoods. Sixty-six percent of black children born between 1985 and 2000 were raised in neighborhoods with a poverty rate of at least $20 \%$, compared to only $6 \%$ of white children. The families of these children have more difficulty finding and accessing safe housing and, when needed, in securing mental health care (U.S. Department of Health and Human Services, 2014).

Poverty impacts education outcomes for children, and students of color fare worse than poor white children. Nearly three quarters of lower income 
4th and 8th grade students cannot read or compute basic mathematics at grade level, compared to only half of higher income (middle and upper) students. Seventy-eight percent of public school students graduated high school in four years in 2010, much lower for Hispanic students (70\%) and black students $(66 \%)$. More difficult for the family is that young children in poor families, compared to non-poor families, are two times more likely to have behavioral, developmental, or social delays (Children's Defense Fund, 2014). Many families living in poverty, or near poverty, also experience homelessness, with 1.2 million public school students experiencing homelessness during the 2011-2012 school year. If a child experiences homelessness, moreover, they are twice as likely to have moderate to severe health problems, to repeat a school grade, and to drop out of high school (National Low Income Housing Coalition, 2013).

\section{Domestic violence/Criminality}

Families with the following traits or characteristics increase the chance for their children or adolescents to commit delinquent acts: lower parental education levels; families that move often or provide different caregivers for the child (e.g., early loss of a parent); families who experience domestic violence; families with members who are involved in criminal activities, including substance abuse; and families with a history of abuse or neglect (Loeber, Farrington, \& Petechuk, 2003; Pogarsky, Lizotte, \& Thornberry, 2003; U.S. Department of Health and Human Services, 2001). Of these, one of the strongest risks for adolescent delinquency and young adult crime is intra-familial violence, including domestic violence or spousal/partner abuse. These experiences have been linked to adolescent aggressive behaviors; whereby young people learn this behavior from family members (Dembo, et al., 2000; Dong et al., 2004; Hawkins, et al., 2000).

Domestic violence acts can be either witnessed by a family member, or the family member could be the victim of the threats, assaults, and/or battering. These domestic violence problems include emotional abuse, threatened and actual physical abuse, or sexual violence between adults (by both heterosexual and same-sex partners). Between three and ten million children are exposed to domestic violence in the United States annually, encompassing 9 to $10 \%$ of the child and adolescent population that witnessed a serious violent act between their parents or caregivers, with a majority of these children being younger than nine years of age (The National Child Traumatic Stress Network, 2016; Sickmund \& Puzzanchera, 2015).

\section{Deaths: Violent and nonviolent}

Violent deaths of family members and loved ones can especially be traumatic to children and young adults. These types of deaths are caused by 
different events, many suicides and homicides. In 2013, over 41,000 people committed suicide and 16,000 people were homicide victims in the United States (Centers for Disease Control and Prevention, 2014). Over 18\% of adolescents nationwide have lost a family member or close friend to a type of homicide. These homicides included criminal homicide, vehicular homicide, and negligent homicide, among others. When such death impacts young children, it may cause what is called traumatic grief, whereby the child cannot understand the death and experiences very severe grief symptoms that lead to frightening thoughts and images of the deceased (Rheingold, Zimrow, Hawkins, Saunders, \& Kilpatrick, 2011).

Nonviolent deaths, which can be by natural causes or accidents, might also be traumatic and difficult situations for children and young adults, particularly when this entails the death of a family member, parent, or peer. Death is often difficult for young people to understand and without support, and many often struggle to adapt to the new situation. Children and adolescents most at risk for nonviolent death trauma experiences include those who were close physically and/or emotionally to the deceased, those with preexisting mental health issues, those with preexisting family difficulties or previous loss experiences, and those with a limited support network (Goodman, 2002).

\section{Witnessing violence}

Witnessing violent acts is common for many children and young adults and has serious repercussions for young people including trauma-induced fears, mental health difficulties, increased risk for substance use, and delinquent behaviors. Seventy percent of older adolescents reported they had witnessed at least one act of violence in their lifetime (Cuevas, Finkelhor, Shattuck, Turner, \& Hamby, 2013; Finkelhor, Ormrod, \& Turner, 2009). Nearly $40 \%$ of adolescents have reported witnessing at least one serious community-based violent act (such as shooting, stabbing, or robbery, among others) over their lifetime, with boys more likely than girls to report witnessing such act (McCart, Zajac, Danielson, Strachan, Ruggiero, Smith, et al., 2011; Zimrow, Ruggiero, Resnick, Hanson, Smith, Saunders, \& Kirkpatrick, 2009).

\section{Race/Ethnicity disparities in delinquency and crime}

Adolescents of color (as well as young adults in the criminal justice system) are over-represented at each decision-making point within the juvenile justice system, from arrest to charges to disposition, with the greatest racial and ethnic disparities the further a youthful offender penetrates the system. Nationwide, black youthful offenders are referred to the juvenile courts for 
delinquency at a rate $140 \%$ greater than white youthful offenders. If adjudicated and supervised youthful offenders continue through the juvenile justice system to out-of-home placement, moreover, the disparity becomes even more stark: blacks and Hispanics represent one-third of this country's adolescent population, but more than two-thirds of those held in juvenile incarceration facilities (Hockenberry \& Puzzanchera, 2014; National Council on Crime and Delinquency, 2007; Puzzanchera \& Robson, 2014; Vazsonyi \& Chen, 2010). Of the youthful offenders incarcerated who are minorities, approximately $60 \%$ are black, $33 \%$ are Hispanic, and, depending on the jurisdiction, between 1 and $4 \%$ are American Indian or Asian. These disparities are found in nearly all states with a greater impact on minority males than females (Office of Juvenile Justice and Delinquency Prevention, 2014; Piquero, 2008).

Most adult criminals begin their careers as youthful offenders. A number of factors predict involvement with the adult criminal courts, mostly related to the onset and persistence of youthful offending behaviors. These include adolescents whose offending behaviors start early and continue through later teen years; who commit more offenses (primarily person and violent types); are more frequently adjudicated delinquent; and whose offenses escalate over time (Aizer \& Doyle, 2013; Loeber \& Farrington, 2008). In some jurisdictions, both serious and low-level youthful offenders who were incarcerated in juvenile facilities, compared to those who received nonincarcerated sentences, were three times more likely to be incarcerated in adult facilities. For low-level youthful offenders, it is the incarceration experience itself that is a precipitating future crimes, often more serious in nature. If more serious youthful offenders do not desist these negative patterns, but continue their involvement with the criminal courts as adults, their prospects are often bleak (Pew Center on the States, 2011; Trulson, Haerle, DeLisi, \& Marquart, 2011).

\section{Immigrant status as a protective factor against delinquency and crime}

For a number of reasons-unreliable reporting, little incentive by local jurisdictions, and the politicization of immigration, among others-there is little valid data on the number of immigrant young people involved in the juvenile justice (or adult criminal) system (The Annie E. Casey Foundation, 2014). On the contrary, there is extensive evidence that criminal involvement among first generation, adult immigrants is lower than for the native born, that immigration itself is not associated with increases in crime rates, and that neighborhoods with greater concentrations of immigrants have lower crime rates (Adelman, Reid, Markle, Weiss, \& Jaret, 2017; Bersani, 
2014; Desmond \& Kubrin, 2009; Graif \& Sampson, 2009; Kubrin \& Ishizawa, 2012; Martinez, 2009).

While there is relatively limited research on the immigrant youthful offending population, there is similar growing evidence that young people in immigrant communities experience less crime and violence and that newly arrived and first generation immigrant youth are less likely to offend than subsequent generations (Bui, 2011; Kubrin \& Desmond, 2015; Morenoff \& Astor, 2006; Peguero \& Chavez, 2015). In particular, first-generation Latino youth are less likely to report negative life experiences, including crime and delinquency (offending, victimization, and drug use) compared to second-generation or higher Latino youth (Chappin \& Brook, 2001; Gibson \& Miller, 2010; Miller, 2012). Though a more recent analysis of the National Longitudinal Study of Adolescent Health found agreement with prior research that first-generation Latino youth were less likely to have police contact, and detention; however, these more recently arrived immigrant youth were more likely than native-born Latino youth to be convicted (Miller, 2015).

In light of research findings to date on race/ethnicity, immigration, trauma, and delinquency/crime, it is important to continue to investigate why and how these experiences are interrelated. The following two specific questions are examined in this study:

1. How does race/ethnicity and citizenship status relate to engagement in crime?

2. How does childhood and adolescent trauma explain the expected associations among race/ethnicity, citizenship status, and crime for young people in the United States?

\section{Method}

\section{Data and sample}

The sample used to examine the research questions comes from the National Longitudinal Survey of Youth 1997 (NLYS97), which is one of the seven cohorts of the National Longitudinal Survey. NLSY97 follows youth who were born between 1980-1984 and were between the ages 12 and 17 years old in 1997 at the time of the first interview. The Round 17 (2015-2016) data became available recently, at which round respondents were between the ages 30 to 36 years old. The original cohort included 8,984 respondents in 1997 . The National Longitudinal Surveys overall have an impressive retention rate with almost $80 \%(n=7,103)$ of original respondents completing the interview for Round 17. This study is based on these 7,103 respondents who completed Round 17 interview. 
NLSY97 is based on a nationally representative sample of the youth in the United States with additional respondents who are Hispanic or Latino or black to oversample minority youths from the population to increase the representation of these minority youths. Unlike other national-level delinquency studies (such as the Monitoring the Future and the Youth Risk Behavior Surveillance System), the NLSY97 selects random samples at the household level instead of at the school level, and therefore, it includes underrepresented populations of "at-risk" youth who are often left out of delinquency studies because of their absences, suspension, dropping out, or being kicked out of school.

\section{Measures}

\section{Socio-Demographic variables}

Four sociodemographic variables that are often related to delinquency were created as control variables and included in all analyses. Gender is a dummy variable where males were coded one $(49.6 \%)$ and females were coded zero $(50.4 \%)$. Race/ethnicity ${ }^{2}$ is measured as a series of following three dummy variables: non-Hispanic black (27.5\%), Hispanic (21.0\%), and non-Hispanic other (3.3\%), while non-Hispanic white (48.2\%) is treated as a reference group in all analyses. Age is an interval ratio variable that measures respondents' age at Round 17 collected in 2015-2016 with a mean of 32.92 and a standard deviation of 1.44 years old. Socioeconomic status $\left(S E S^{3}\right)$ is a dummy and proxy variable that measures respondents' socioeconomic status where respondents with at least one biological or resident parent who earned a college degree or higher were coded one $(48.2 \%)$, and all others were coded zero (51.8\%); education status is significantly associated with family or household income (The Pell Institute, 2017). All of these control variables, except for age, were created using Round 1 data collected in 1997.

\section{Citizenship status}

Respondents' citizenship status ${ }^{4}$ is a dummy variable and was measured similarly to how the study by Bersani (2014) measured the first-generation immigrants, where those who were born in the United States were coded as one $(87.6 \%)$ and all others were coded zero (12.4\%). Those who were not born in the United States included respondents who were not born in the United States, but maybe naturalized citizens, and those who could not determine their birthplace. For the vast majority of respondents, their citizenship status was determined based on the information from the first round of data collected in 1997 (see Footnote 4 for information on cases with a missing value on citizenship status). As expected, respondents' 
citizenship status and race/ethnicity ${ }^{5}$ were significantly correlated with one another $(r=-0.43, p<0.001)$. A cross-tab analysis of the racial and ethnic composition of those who were not born in the United States shows that the majority of them identified themselves as Hispanics $(71.8 \%)$, while about an equal proportion (9-10\%) of the remaining respondents identified as each of the other three groups (i.e., non-Hispanic whites, non-Hispanic blacks, and non-Hispanic other).

\section{Trauma}

Several items from various different sections of NLSY97 were used to measure respondents' experience with trauma. First, between 2002 to 2013, NLSY97 collected five rounds of information on respondents' experiences with stressful events. In order to focus on childhood trauma, only Round 5 data collected in 2002, the oldest round of data available for this information, when respondents were between the ages of 18 and 22 years old, were used. Each of the following five stressful-life-events was measured as "yes" $(=1)$ or "no" $(=0)$ of having experienced in the last five years prior to the interview in 2002: the death of a parent, a step-parent, a brother, or a sister (4.3\% said "yes"); violent crime victimization (6.4\% said "yes"); homelessness (1.4\% said "yes"); incarceration of any adult household member (6.0\% said "yes"); and parental unemployment (12.1\% said "yes"). Second, the data from Round 5 collected in 2002 on whether or not respondents have seen someone getting shot when respondents were between the ages of 12 and 18 years old $(2.3 \%$ said "yes" $=1)$ were also examined. Third, whether or not respondents' household income was below the poverty level in the previous year $(17.5 \%$ said "yes" $=1)$ based on the data from Round 5 collected in 2002 was also included. Reliability among these seven trauma items was expectedly low (Cronbach's alpha $=0.26$ ) because these traumatic experiences do not necessarily occur together. In order to capture the cumulative effect of trauma, which past studies indicate has a profound impact on one's life (Finkelhor, Turner, Shattuck, \& Hamby, 2013), a trauma scale was created by summing the z-score transformations of each of the seven trauma events ${ }^{6}$. Trauma scale had a mean of zero and a standard deviation of 3.05 .

\section{Engagement in crime}

Respondents' engagement in the following six law-breaking behaviors was examined: "destroying property," "stealing something less than $\$ 50$ in value," "stealing something more than $\$ 50$ in value," "other property crimes," "attacking or assaulting someone," "selling illegal drugs." In order to examine how the experience with trauma in 1998-2002 is related to the 
Table 1. Descriptive Statistics of Criminal Behaviors, $n=6,842$.

\begin{tabular}{lllc}
\hline Behaviors & Mean & S.D. & Factor loading \\
\hline Destroyed property & 0.08 & 0.38 & 0.697 \\
Stole less than \$50 & 0.12 & 0.53 & 0.767 \\
Stole more than \$50 & 0.05 & 0.29 & 0.778 \\
Engaged in other property crime & 0.04 & 0.24 & 0.735 \\
Attacked or assaulted & 0.15 & 0.56 & 0.655 \\
Sold drugs & 0.19 & 0.81 & 0.669 \\
Crime scale & 0 & 4.32 & \\
\hline
\end{tabular}

engagement in these law-breaking behaviors, a total number of years of engagement in these law-breaking behaviors between 2003-2015 was created using 11 rounds of data $^{7}$. For each of the above six law-breaking behaviors, the number of years respondents have engaged in the behavior was calculated by summing the number of "yes" responses (which indicates that they have engaged in the behavior in the past year). Descriptive statistics of each of the six law-breaking behaviors are shown in Table 1. A confirmatory factor analysis with principal component analysis indicates a single factor with the first three eigenvalues of 3.09, 0.84, and 0.69 (factor loadings are shown in Table 1). A reliability analysis indicates a moderately strong reliability with Cronbach's alpha of 0.75 . A scale measuring crime was created by summing the z-score transformations of each of the six behaviors. Crime scale had a mean of 0.00 and a standard deviation of 4.32 .

\section{Results}

In what follows, Ordinary Least Squares Regression (OLS) analysis is used when the dependent variable is a scale, Binary Logistic Regression analysis is used when the dependent variable is a dummy variable, and Multivariate General Linear Model (MGLM) analysis is used when we analyze the dependent variables not as a scale to answer the two research questions. All multivariate models are assessed for assumptions and analyzed with collinearity diagnostics to test for a multicollinearity. All models reported were with variables that had variance inflation factors (VIFs) of less than 2.5, which is less than the rule of thumb commonly used (Allison (1999).

\section{Citizenship and race/Ethnicity}

In order to examine the difference in the engagement in crime by citizenship status, crime was regressed on citizenship status and control variables (see Model 1, Table 2). As expected and consistent with previous studies (but contrary to the popular belief), those who were born in the United States are significantly more likely to engage in crime $(\beta=0.34, p=0.005)$ than those who were not born in the United States. Moreover, the effect of 
Table 2. Multiple Regression Analyses with Crime as the Dependent Variable, $n=6,842$.

\begin{tabular}{|c|c|c|c|c|c|c|c|c|c|}
\hline \multirow[b]{2}{*}{ Variables } & \multicolumn{3}{|c|}{ Model 1} & \multicolumn{3}{|c|}{ Model 2} & \multicolumn{3}{|c|}{ Model 3} \\
\hline & $b$ & $p$ & $\beta$ & $b$ & $p$ & $\beta$ & $b$ & $p$ & $\beta$ \\
\hline Intercept & 3.058 & * & & 2.734 & * & & 2.386 & * & \\
\hline Gender (male $=1$ ) & 0.960 & $* * *$ & 0.111 & 0.962 & $* * *$ & 0.111 & 0.945 & $* * *$ & 0.109 \\
\hline Age & -0.155 & $* * *$ & -0.038 & -0.115 & $* * *$ & -0.038 & -0.103 & $* *$ & -0.034 \\
\hline SES (college degree or higher $=1$ ) & -0.259 & $*$ & -0.030 & -0.184 & & -0.021 & -0.026 & & -0.003 \\
\hline Citizenship (U.S. born = 1) & 0.447 & $* *$ & 0.034 & 0.634 & $* * *$ & 0.048 & 0.578 & $* * *$ & 0.044 \\
\hline \multicolumn{10}{|l|}{$\begin{array}{l}\text { Race/ethnicity dummy variables (ref- } \\
\text { erence group is non- } \\
\text { Hispanic white) }\end{array}$} \\
\hline Black & & & & 0.140 & & 0.014 & -0.047 & & -0.005 \\
\hline Hispanic & & & & 0.412 & $* *$ & 0.039 & 0.284 & & 0.027 \\
\hline Other minorities & & & & -0.154 & & -0.006 & -0.264 & & -0.011 \\
\hline Trauma & & & & & & & 0.211 & $* * *$ & 0.149 \\
\hline Adjusted $R^{2}$ & 0.015 & & & 0.016 & & & 0.037 & & \\
\hline
\end{tabular}

${ }^{*} p<0.05$.

$*^{*} p<0.01$.

$* * * p<0.001$. 
citizenship status on engagement in crime became stronger $(\beta=0.48$, $p<0.001$ ) after taking into account respondents' race/ethnicity (see Model 2 , Table 2). The results also indicate that blacks do not significantly differ in terms of the likelihood of engagement in crime, or blacks are no more likely than whites to engage in crime. Hispanics are, on the other hand, more likely to engage in crime $(\beta=0.39, p=0.009)$ than whites, controlling for citizenship status. Citizenship status overall has a much stronger effect on engagement in crime (i.e., the fact that those who were born in the United States are more likely than those who were not born in the United States to engage in crime) than the effect of being Hispanic on engagement in crime (i.e., the fact that Hispanics are more likely than whites to engage in crime).

\section{Trauma}

Before examining the effect of experience with childhood trauma on the engagement in crime, trauma was regressed on control variables and citizenship status (see Model 1, Table 3). Contrary to the expectation, there was no significant difference in the trauma experiences by citizenship status between those who were born in the United States and those who were not born in the United States. A closer examination with the Binary Logistic Regression analysis with each trauma event regressed separately (results not shown), however, indicates that those who were born in the United States experienced a significantly higher odds of "death of family members" $(O R=1.79, p=0.007)$ and "homelessness" $(O R=3.47, p=0.015)$ but a significantly lower odds of "poverty" $(O R=0.61, p<0.01)$ than those who were not born in the United States. When the overall trauma scale was examined, and therefore, these contradictory results might have canceled out the citizenship status difference in trauma.

Table 3. Multiple Regression Analyses with Trauma as the Dependent Variable, $n=6,842$.

\begin{tabular}{|c|c|c|c|c|c|c|}
\hline \multirow[b]{2}{*}{ Variables } & \multicolumn{3}{|c|}{ Model 1} & \multicolumn{3}{|c|}{ Model 2} \\
\hline & $b$ & $p$ & $\beta$ & $b$ & $p$ & $\beta$ \\
\hline Intercept & 2.247 & $* *$ & & 1.649 & * & \\
\hline Gender (male $=1$ ) & 0.068 & & 0.011 & 0.080 & $* * *$ & 0.013 \\
\hline Age & -0.058 & $*$ & -0.027 & -0.059 & * & -0.028 \\
\hline SES (college degree or higher $=1$ ) & -0.945 & $* * *$ & -0.155 & -0.750 & $* * *$ & -0.123 \\
\hline Citizenship (U.S. born $=1$ ) & 0.096 & & 0.010 & 0.267 & * & 0.029 \\
\hline \multicolumn{7}{|c|}{ Race/ethnicity dummy variables (reference group is non-Hispanic white) } \\
\hline Black & & & & 0.888 & $* * *$ & 0.130 \\
\hline Hispanic & & & & 0.611 & $* * *$ & 0.082 \\
\hline Other minorities & & & & 0.521 & * & 0.031 \\
\hline Adjusted $R^{2}$ & 0.024 & & & 0.038 & & \\
\hline
\end{tabular}


In the next model with the trauma scale as the dependent variable, three race/ethnicity dummy variables were included in the model alongside citizenship status (see Model 2, Table 3). As expected, all racial/ethnic minority groups, especially blacks, reported a significantly higher level of childhood trauma experiences than whites $(\beta=0.13, p<0.001$ for blacks, $\beta=0.08$, $p<0.001$ for Hispanics, and $\beta=0.03, p=0.013$ for other). The results indicate, moreover, that being black is more important in explaining the likelihood of experiencing childhood trauma than parental socioeconomic status measured in terms of education levels $(\beta=-0.12, p<0.001)$. Interestingly, citizenship status became significant $(\beta=0.03, p=0.036)$, after controlling for race/ethnicity, and indicated that those who were born in the United States experienced a significantly higher level of childhood trauma than those who were not born in the United States. The change in significance for citizenship status is most likely explained by the significant relationship being Hispanic (who are the majority of those who are not born in the United States) has on trauma experience that was taking into account in the second model.

The Binary Logistic Regression analysis with each trauma event examined separately as the dependent variable (results not shown) overall confirms the differences by in race/ethnicity in the overall trauma experience. Blacks had a significantly higher odds of experiencing "death of family members" ( $O R=1.82, p<0.001)$, "unemployment" $(O R=1.66, p<0.001)$, "seen someone getting shot" $(O R=2.46, p<0.001)$, and "poverty" $(O R=3.37, p<0.001)$ than whites. Similarly, Hispanics had a significantly higher odds of experiencing "incarceration of family members" ( $O R=1.63$, $p=0.001)$, "unemployment" $(O R=1.29, p=0.025)$, "seeing someone getting shot" ( $O R=1.84, p=0.016)$, and "poverty" $(O R=2.65, p<0.001)$ than whites. Finally, other racial/ethnic minorities had a significantly higher odds of experiencing "unemployment" $(O R=1.55, p=0.033)$ than whites. Overall, as expected from past studies, racial/ethnic minorities, especially among blacks and Hispanics, are significantly more likely than whites to experience being poor.

\section{Engagement in crime}

In order to examine the effect trauma has on engagement in crime, crime was regressed on citizenship status and trauma (see Model 3, Table 2). As expected, trauma has a significantly positive effect on engagement in crime $(\beta=0.15, p<0.001)$, even stronger than the effect of gender on crime $(\beta=0.11, p<0.001)$. An additional analysis separated by gender and race/ ethnicity with citizenship status controlled (not shown) further indicates that trauma is significantly and positively related to engagement in crime 
among all eight groups: white males $(\beta=0.14, p<0.001)$, black males $(\beta=0.22, p<0.001)$, Hispanic males $(\beta=0.17, p<0.001)$, other racial/ethnic minority males $(\beta=0.23, \quad p<0.001)$, white females $(\beta=0.12$, $p<0.001)$, black females $(\beta=0.12, p<0.001)$, Hispanic females $(\beta=0.15$, $p<0.001)$, and other racial/ethnicity females $(\beta=0.20, p=0.038)$. However, another analysis separated by gender and citizenship status with race/ethnicity controlled (not shown) indicates that trauma is significantly and positive related to engagement in crime only among those who were both in the United States for both males $(\beta=0.19, p<0.001)$ and females $(\beta=0.13, p<0.001)$. Trauma on the other hand had no significant relationship with engagement in crime among either genders of those who were not born the United States.

Trauma, however, could not explain away the effect of citizenship status on crime $(\beta=0.04, p=0.013)$, which is understandable given that there was no citizenship status difference in trauma overall. Even when the three trauma events that were significantly related to citizenship status were examined separately (results not shown), they could not explain away the fact that those who were born in the United States are more likely than those who were not born in the United States to engage in crime. On the other hand, trauma explained away the effect of being Hispanic on engagement in crime, which is consistent with the earlier results that showed that all race/ethnicity minority groups, including Hispanics, experienced a significantly higher level of childhood trauma than whites. Interestingly, though blacks and other racial/ethnic minority group experienced a significantly higher level of childhood trauma than whites, they did not engage in a higher level of crime than whites.

\section{Engagement in crime by gender}

The same three models from Table 1 with crime as the dependent variable with control variables and citizenship were run separately by gender (see Table 4). The results indicate that citizenship status is significantly related to engagement in crime only among females, with females who were born in the United States being significantly more likely than females who were not born in the United States to engage in crime $(\beta=0.07, p<0.001$ for Model 3). Citizenship status remained significant among females even after controlling for racelethnicity and trauma. None of the race/ethnicity dummy variables were significant among either males or females. Though trauma could not explain away the gender difference in engagement in crime, trauma had a significant positive effect on crime engagement among both males $(\beta=0.17, p<0.001)$ and females $(\beta=0.12, p<0.001)$. Childhood trauma experience overall explained about $2.8 \%$ of variation 
Table 4. Multiple Regression Analyses with Crime as the Dependent Variable by Gender.

\begin{tabular}{|c|c|c|c|c|c|c|c|c|c|}
\hline \multicolumn{10}{|c|}{ Males $(n=3,396)$} \\
\hline \multirow[b]{2}{*}{ Variables } & \multicolumn{3}{|c|}{ Model 1} & \multicolumn{3}{|c|}{ Model 2} & \multicolumn{3}{|c|}{ Model 3} \\
\hline & $b$ & $p$ & $\beta$ & $b$ & $p$ & $\beta$ & $b$ & $p$ & $\beta$ \\
\hline Intercept & 5.210 & $* *$ & & 4.913 & $*$ & & 4.649 & * & \\
\hline Age & -0.147 & $*$ & -0.042 & -0.148 & * & -0.042 & -0.137 & * & -0.039 \\
\hline $\begin{array}{l}\text { SES (college degree or higher } \\
\quad=1 \text { ) }\end{array}$ & -0.419 & $*$ & -0.042 & -0.300 & & -0.030 & -0.115 & & -0.011 \\
\hline Citizenship (U.S. born $=1$ ) & 0.360 & & 0.024 & 0.514 & & 0.034 & 0.447 & & 0.029 \\
\hline \multicolumn{10}{|l|}{$\begin{array}{l}\text { Race/ethnicity } \\
\text { dummy variables }\end{array}$} \\
\hline Black & & & & 0.258 & & 0.023 & -0.075 & & -0.007 \\
\hline Hispanic & & & & 0.490 & & 0.040 & 0.297 & & 0.024 \\
\hline Other minorities & & & & -0.658 & & -0.023 & -0.811 & & -0.029 \\
\hline Trauma & & & & & & & 0.277 & $* * *$ & 0.172 \\
\hline Adjusted $R^{2}$ & 0.003 & & & 0.004 & & & 0.032 & & \\
\hline \multicolumn{10}{|l|}{ Females $(n=3,446)$} \\
\hline Variables & Model 1 & & & Model 2 & & & Model 3 & & \\
\hline & $b$ & $p$ & $\beta$ & $b$ & $p$ & $\beta$ & $b$ & $p$ & $\beta$ \\
\hline Intercept & 1.939 & & & 1.601 & & & 1.272 & & \\
\hline Age & -0.086 & $*$ & -0.036 & -0.084 & * & -0.036 & -0.073 & & -0.031 \\
\hline $\begin{array}{l}\text { SES (college degree or higher } \\
\quad=1 \text { ) }\end{array}$ & -0.104 & & -0.015 & -0.071 & & -0.010 & 0.045 & & 0.007 \\
\hline Citizenship (U.S. born = 1) & 0.527 & $* *$ & 0.051 & 0.734 & $* * *$ & 0.071 & 0.692 & $* * *$ & 0.067 \\
\hline \multicolumn{10}{|l|}{$\begin{array}{l}\text { Race/ethnicity dummy varia- } \\
\text { bles (reference group is } \\
\text { non-Hispanic white) }\end{array}$} \\
\hline Black & & & & 0.028 & & 0.004 & -0.054 & & -0.007 \\
\hline Hispanic & & & & 0.331 & & 0.039 & 0.258 & & 0.031 \\
\hline Other minorities & & & & 0.341 & & 0.018 & 0.275 & & 0.014 \\
\hline Trauma & & & & & & & 0.139 & $* * *$ & 0.121 \\
\hline Adjusted $R^{2}$ & 0.003 & & & 0.003 & & & 0.017 & & \\
\hline
\end{tabular}

$* p<0.05$.

$*^{* *} p<0.01$.

$* * * p<0.001$. 
Table 5. Multivariate Multiple Regression Analysis with Six Criminal Behaviors as the Dependent Variables, $n=6,842$.

\begin{tabular}{|c|c|c|c|}
\hline Variables & Pillai's Trace & $\mathrm{F}$ & $p$ \\
\hline Intercept & 0.004 & 4.474 & $* * *$ \\
\hline Gender $($ male $=1)$ & 0.003 & 3.641 & $* * *$ \\
\hline Age & 0.003 & 3.239 & $* *$ \\
\hline SES (college degree or higher $=1$ ) & 0.001 & 0.602 & \\
\hline Citizenship (U.S. born = 1) & 0.001 & 0.870 & \\
\hline \multicolumn{4}{|c|}{ Race/ethnicity dummy variables (reference group is non-Hispanic white) } \\
\hline Black & 0.000 & 0.398 & \\
\hline Hispanic & 0.001 & 0.798 & \\
\hline Other minorities & 0.000 & 0.398 & \\
\hline
\end{tabular}

among males and $1.4 \%$ of variation among females in engagement in crime, as indicated by the change in $R^{2}$ values from Model 2 to Model 3 in Table 4.

Finally, using the Binary Logistic Regression analysis, the relationships among citizenship status, race/ethnicity, experience with childhood trauma, and the engagement in six criminal behaviors were examined for males and females separately. Only some of the results are shown in Table 5. Results are overall similar to and confirm the results discussed in the previous section shown in Table 4. For both genders, trauma had a significant relationship with engagement in all six criminal behaviors. Citizenship status was significant only among females once again, indicating that women who were born in the United States are significantly more likely than women who were not born in the United States to engage in "stealing something less than $\$ 50$ " $(F=5.42, p=0.020)$, "attacking or assaulting" $(F=6.05$, $p=0.014)$, and "selling drugs" $(F=4.62, p=0.032)$, prior to controlling for race/ethnicity. Once race/ethnicity is controlled, however, citizenship status became no longer significant with any of the six criminal behaviors among females.

\section{Discussion}

This study examined race/ethnicity and citizenship status differences in engagement in delinquency and crime through childhood and adolescent trauma. The following two specific research questions were examined: (1) how do race/ethnicity and citizenship status relate to engagement in crime and (2) how does childhood and adolescent trauma explain the expected associations among race/ethnicity, citizenship status, and crime? Along with other research literature to date, the study's findings related to these two questions generate four major implications and offer suggestions for future study. 
First, as far as the six law-breaking behaviors this study examined (including "destroying property," "stealing something less than $\$ 50$ in value," "stealing something more than $\$ 50$ in value," "other property crimes," "attacking or assaulting someone," and "selling illegal drugs"), there was no difference in the likelihood of engagement in these behaviors between blacks and whites. Though this finding is consistent with early other selfreport studies that examined less serious delinquents (Elliott, Huizinga, \& Menard, 1989), it is not what one might expect from the disproportionate criminal justice involvement among blacks compared to whites (Hockenberry \& Puzzanchera, 2014); though significant other explanations for this disproportionate involvement have been investigated (Piquero, 2008). The lack of race/ethnicity difference in crime might be explained by the way the engagement in crime was measured in this study, as the total number of years respondents have engaged in each of the six law-breaking behaviors. This means that someone who engaged in a law-breaking behavior numerous times in the past year was counted the same as someone who engaged in the same behavior once in the same time period. Further investigation of this phenomenon with the NLYS, including longitudinal designs are recommended.

Second, the cumulative experience of childhood trauma, involving seven events (including "the death of a parent, a step-parent, a brother, or a sister," "violent crime victimization," "homelessness," "incarceration of any adult household member," "parental unemployment," "seen someone getting shot when respondents were between the ages of 12 and 18 years old," and "household income was below the poverty level in the previous year") is significantly and positively related to the engagement in delinquency and crime, indicating that those who experienced childhood and/ or adolescent trauma are significantly more likely to engage in delinquency and crime than those who did not experience childhood trauma. This is consistent with the findings from Agnew general strain theory, which considers "loss of positive stimuli" (e.g., death of love one) and "presentation of negative stimuli" (e.g., criminal victimization) as sources of strain that might lead to engagement in crime. Agnew's sources of strain found significantly related to crime and delinquency are similar to many of the childhood trauma events examined in this study. Childhood trauma was even more strongly related to the engagement in delinquency and crime than one of the strongest and consistent correlates of delinquency, gender. The significant relationship was found for both males and females and for all racial/ethnic groups (including whites, blacks, Hispanics, and other).

Third, Hispanics are significantly more likely than whites to engage in delinquency and crime, even after controlling for citizenship status; 
however, this ethnicity difference in delinquency and crime engagement was explained away by their higher level of childhood trauma experiences than whites. Indeed, all racial and ethnic minority groups compared to whites reported a significantly higher level of childhood trauma experiences, though blacks and other minorities are no more likely than whites to engage in delinquency and crime, even before controlling for childhood trauma.

Fourth, citizenship status is significantly related to the likelihood of engagement in delinquency and crime but, contrary to the common belief but consistent with numerous empirical studies (Bui, 2011; Peguero \& Chavez, 2015), it is the native-born who are more likely to engage in delinquency and crime compared to those who are born outside of the United States. After taking into account respondents' race/ethnicity, the effect of citizenship status on engagement in crime became even stronger, which is likely explained by the significant relationship that being Hispanic (who are the majority of those who are not born in the United States) has on engagement in crime that was taking into account in the second model.

A closer analysis separated by gender, moreover, indicates that the citizenship status difference in the engagement in delinquency and crime was significant only among women. Specifically, women who were born in the United States are significantly more likely to engage in at least some of the law-breaking behaviors ("stealing something less than $\$ 50$," "attacking or assaulting," and "selling drugs") than women who were born outside of the United States. Among men, there was no difference in engagement in delinquency and crime between those who were born in the United States compared to those who were born outside of the UnitedStates. Because there was no citizenship status difference in trauma when trauma was examined cumulatively, it is understandable that trauma could not explain away the effect of citizenship status on delinquency and crime engagement among women.

This finding of no difference in crime engagement for young adult males and citizenship status may also need to be reviewed as preliminary, in that, as noted, researchers more consistently found delinquency and crime rates significantly lower for those born outside the United States (Bui, 2011; Kubrin \& Desmond, 2015; Morenoff \& Astor, 2006; Peguero \& Chavez, 2015). However, as this area continues to be investigated, some have found that it may be more difficult to explain why this is the case in immigrant communities, or what factors mediate or suppress adolescent violence (Kubrin \& Desmond, 2015). Theoretical applications or explanations for immigrant status and adolescent delinquency/violence also need further investigation, with the impact of culture and using the routine activities theory to help discern additional research hypotheses (Mallett \& Fukushima-Tedor, 2019). 


\section{Limitations}

There are several limitations to the study data and methodology. While the NLSY is considered one of the more important national databases on adolescents and young adults available to researchers, the 1997 sample was selected based on geographic housing units, and oversampled black and Hispanic/Latinos. This study did not weight the sample for its analysis, limiting some of the findings generalizations. In addition, a possible limitation is that the constructed trauma variable has lower than desired construct validity; however, this was utilized because of the importance of the research hypotheses to the literature and other variables included in the modeling. And, last, the models did not explain a significantly large variance in the interested outcomes, asking that more research hypotheses and additional predictor variables be pursued.

\section{Conclusion}

Many questions remain concerning the impact that race/ethnicity has on delinquency and crime. While the disproportionate outcomes and racial and ethnic disparities have been known and of concern for decades, answers to this conundrum are much more difficult to identify. Additionally, the focus in more recent years on immigration and crime, including the politicization and misrepresentation of research findings showing that first-generation immigrants are less likely to engage in delinquency and crime, require continued dialog and explication of these outcomes beyond academe. It is important to continue to investigate and expand the empirical datasets on race/ethnicity, citizenship status, trauma, and gender, but to also find effective ways to broaden the public discourse.

\section{Notes}

1. Excludes Alaska and Hawaii (both of which have a different guideline).

2. Race/ethnicity was created by combining an item measuring respondents' race (which included "white," "black or African American," "American Indian," "Eskimo," or "Aleut, Asian Pacific Islander," and "something else") and an item measuring respondents' ethnicity (which included "black," "Hispanic," "Mixed race (nonHispanic)," and "non-black/non-Hispanic") from Round 1 collected in 1997. These two items were cross-examined to create the combined race/ethnicity variable used in this study. Respondents' race item had 59 respondents with a missing value, of which 43 were identified as "Hispanic" based on respondents' answer to the ethnicity item. The remaining 16 respondents with a missing value on respondents' race item identified as mixed race in respondents' ethnicity item, thus, were included in "other" race/ethnicity.

3. SES was created using four items from Round 1 collected in 1997, including the highest education level of each of the following parental figure: biological father, 
biological mother, residential father, and residential mother. Of 274 respondents who had a missing value on all four of these items, 13 respondents whose total household income level in 1997 was below the poverty line were given zero or "having no parental figure with a college degree or higher" on SES. The remaining 261 respondents were deleted from the sample.

4. 783 respondents originally had a missing value on their citizenship status from Round 1 data collected in 1997. For these respondents, the citizenship status from the data from subsequent twelve rounds, where respondents' citizenship status was available, all of which measured the citizenship status of respondents based on whether or not they were born in the United States, was used to determine their citizenship status (675 out of 783 identified as citizens born in the United States in at least one of the rounds in the subsequent years). Of the remaining 108 respondents whose citizenship status could not be identified using any of the round of data, 29 identified as a naturalized citizens and 67 identified as not a U.S. citizen based on a different followup question for citizenship from Round 5 data collected in 2001, thus these respondents were coded zero or as "not born in the U.S." for citizenship status. This leaves 12 respondents with a missing value on citizenship status and were also coded zero or as "not born in the U.S." for citizenship status.

5. A nominal variable race/ethnicity includes categories "white," "black," "Hispanic," and "other."

6. A $z$-score was calculated for each of the trauma items in order to standardize them before creating a scale because the "weight" of each trauma item probably varies depending on the seriousness of the trauma event. A z-score was calculated by subtracting the mean of the item from each respondent's score on the item and dividing it by the standard deviation of the item.

7. Because NLS97 interviewed respondents annually but did not ask about law-breaking behaviors in 2012 and 2014, there were a total of 11 rounds of data on these lawbreaking behaviors. In addition, though, Round 15 collected in 2013 and Round 17 collected in 2015 included only three of the six law-breaking behaviors ("stealing something less than $\$ 50$ in value," "stealing something more than $\$ 50$ in value," and "selling illegal drugs").

\section{References}

Adelman, R., Reid, L. W., Markle, G., Weiss, S., \& Jaret, C. (2017). Urban crime rates and the changing face of immigration: Evidence across four decades. Journal of Ethnicity in Criminal Justice, 15(1), 52-77. doi:10.1080/15377938.2016.1261057

Aizer, A., \& Doyle, J. J. Jr. (2013). Juvenile incarceration, human capital, and future crime: Evidence from randomly assigned judges. NBER Working Paper Series. National Bureau of Economic Research, Cambridge, MA.

Allison, P. D. (1999). Multiple regression: A primer. Thousand Oaks, CA: Pine Forge Press.

Bersani, B. (2014). An examination of first and second generation immigrant offending trajectories. Justice Quarterly, 31(2), 315-343. doi:10.1080/07418825.2012.659200

Bui, H. N. (2011). Segmented assimilation: Racial differences in the relationship between immigration status and delinquency. In C.G. Coll \& A. Marks (eds), Is America becoming a developmental risk? (135-158). Washington DC: American Psychological Association.

Centers for Disease Control and Prevention (2014b). Fatal injury reports, 1999-2014. Centers for Disease Control and Prevention, Atlanta, GA. 
Chappin, S. R., \& Brook, J. S. (2001). The influence of generational status and psychosocial variables on marijuana use among black and Puerto Rican adolescents. Hispanic Journal of Behavioral Sciences, 23(1), 22-36. doi:10.1177/0739986301231002

Child Trends. (2015). Indicators on children and youth. Washington DC: Child Trends.

Children's Defense Fund. (2014). The state of America's children. Washington, DC: Children's Defense Fund.

Cuevas, C. A., Finkelhor, D., Shattuck, A., Turner, H., \& Hamby, S. (2013). Children's exposure to violence and the intersection between delinquency and victimization. Washington, DC: Office of Juvenile Justice and Delinquency Prevention, Office of Justice Programs, U.S. Department of Justice.

Currie, J., \& Tekin, E. (2006). Does child abuse cause crime? Andrew Young School of Public Policy, Research Paper Studies. Atlanta, GA: Georgia State University.

Dembo, R., Wothke, W., Shemwell, M., Pacheco, K., Seeberger, W., Rollie, M., ... Livingston, S. (2000). A structural model of the influence of family problems and child abuse factors on serious delinquency among youths processed at a juvenile assessment center. Journal of Child and Adolescent Substance Abuse, 10(1), 17-31. doi:10.1300/ J029v10n01_02

Desmond, S. A., \& Kubrin, C. E. (2009). The power of place: Immigrant communities and adolescent violence. Sociological Quarterly, 50(4), 581-607. doi:10.1111/j.15338525.2009.01153.x

Dong, M., Anda, R. F., Felitti, V. J., Dube, S. R., Williamson, D. F., Thompson, T. J., ... Giles, W. H. (2004). The interrelatedness of multiple forms of childhood abuse, neglect, and household dysfunction. Child Abuse and Neglect, 28(7), 771-784. doi:10.1016/ j.chiabu.2004.01.008

Elliott, D. S., Huizinga, D., \& Menard, S. (1989). Multiple problem youth. New York: Springer-Verlag.

Finkelhor, D., Ormrod, R. K., \& Turner, H. A. (2009). Lifetime assessment of poly-victimization in a national sample of children and youth. Child Abuse \&Amp; Neglect, 33(7), 403-411. doi:10.1016/j.chiabu.2008.09.012

Finkelhor, D., Turner, H., Shattuck, A., \& Hamby, S. L. (2013). Violence, crime, and abuse exposure in a national sample of children and youth: an update. JAMA Pediatrics, 167(7), 614-621. doi:10.1001/jamapediatrics.2013.42

Gibson, C. L., \& Miller, H. V. (2010). Crime and victimization among Hispanic adolescents: A multilevel longitudinal study of acculturation and segmented assimilation. Final report submitted to the National Institute of Justice. NCJ, 232-278.

Goodman, R. F. (2002). Caring for kids after trauma and death: A guide for parents and professionals. New York: The Institute for Trauma and Stress, The New York University Child Study Center.

Graif, C. \& Sampson, J. (2009). Spatial heterogeneity in the effects of immigrationand diversity on neighborhood homicide rates. Homicide Studies, 13(3), 242-260.

Hawkens, J. D., Herrenkohl, T. I., Farrington, D. P., Brewer, D., Catalano, R. F., Harachi, T. W., \& Cothern, L. (2000). Predictors of youth violence. Office of Juvenile Justice and Delinquency Prevention, Office of Justice Programs, U.S. Department of Justice, Washington, DC.

Hockenberry, S., \& Puzzanchera, C. (2014). Juvenile court statistics, 2011. Office of Juvenile Justice and Delinquency Prevention, Office of Justice Programs, U.S. Department of Justice, Washington, DC.

Holzer, H., Schanzenbach, D. W., Duncan, G. G., \& Ludwig, J. (2007). The economic costs of poverty: Subsequent effects of children growing up poor. Washington, DC: Center for American Progress. 
Howell, J. C. (2009). Preventing \& reducing juvenile delinquency: A comprehensive framework (second edition). Thousand Oaks, CA: SAGE Publications.

Kang, H.-K., \& Burton, D. L. (2014). Effects of racial discrimination, childhood trauma, and trauma symptoms on juvenile delinquency in African American incarcerated youth. Maltreatment \& Trauma, 23(10), 1109-1125. doi:10.1080/10926771.2014.968272

Kowalski, R. M., \& Limber, S. P. (2013). Psychological, physical, and academic correlates of cyberbullying and traditional bullying. Journal of Adolescent Health, 53(1), 13-20.

Kubrin, C. E., \& Desmond, S. A. (2015). The power of place revisited: Why immigrant communities have lower levels of adolescent. Violence. Youth Violence and Juvenile Justice, 13(4), 345-366. doi:10.1177/1541204014547590

Kubrin, C. E., \& Ishizawa, H. (2012). Why some immigrant neighborhoods are safer than others: Divergent findings from Los Angeles and Chicago. The ANNALS of the American Academy of Political and Social Science, 641(1), 148-173. doi:10.1177/0002716211431688

Loeber, R., Farrington, D. P., \& Petechuk, D. (2003). Child delinquency: Early intervention and prevention. Juvenile Justice Bulletin, Office of Juvenile Justice and Delinquency Prevention, U.S. Department of Justice, Washington, DC.

Loeber, R., \& Farrington, D. P. (2008). From juvenile offending to young adult offending. IJ$C X-K-42$. National Institute of Justice, Office of Justice Programs, U.S. Department of Justice, Washington DC.

Mallett, C., \& Fukushima-Tedor, M. (2019). Juvenile delinquency: Pathways and prevention. Thousand Oaks, CA: Sage Publications.

Martinez, S. (2009). A system gone berserk: How are zero-tolerance policies really affecting schools? Preventing School Failure, 53(3), 153-157.

McCart, M. R., Zajac, K., Danielson, C. K., Strachan, M., Ruggiero, K. J., Smith, D. W., ... Kilpatrick, D. G. (2011). Interpersonal victimization, posttraumatic stress disorder, and change in adolescent substance use prevalence over a ten-year period in 1995 and 2005. Journal of Clinical Child and Adolescent Psychology, 40(1), 136-143. doi:10.1080/ 15374416.2011 .533411

Miller, H. V. (2012). Correlates of delinquency and victimization in a sample of Hispanic youth. International Criminal Justice Review, 22(2), 153-170. doi:10.1177/ 1057567712444922

Miller, H. V. (2015). Juvenile justice system outcomes among foreign-born and native-born Latinos in the United States: An exploratory study. Youth Violence and Juvenile Justice, 13(4), 428-442. doi:10.1177/1541204014547592

Morenoff, J. D., \& Astor, A. (2006). Immigrant assimilation and crime: Generational differences in youth violence in Chicago. In R. Martinez Jr. \& A. Valenzuela Jr. (Eds.), Immigration and crime: Race, ethnicity, and violence (pp. 36-63). New York: New York University Press.

National Low Income Housing Coalition. (2013). Out of reach, 2013. Washington, DC: National Low Income Housing Coalition.

National Council on Crime and Delinquency. (2007). And justice for some: Differential treatment of youth of color in the justice system. Oakland, CA: National Council on Crime and Delinquency.

Office of Juvenile Justice and Delinquency Prevention. (2014). OJJDP statistical briefing book. Washington, DC: Office of Justice Programs, U.S. Department of Justice.

Peguero, A. A., \& Chavez, J. M. (2015). Special issue introduction for the significance of immigration for youth and their experiences with violence and juvenile justice. Youth Violence and Juvenile Justice, 13(4), 295-298. doi:10.1177/1541204014547588 
Pew Center on the States (2011). State of recidivism: The revolving door of America's prisons. Washington, DC: The Pew Charitable Trusts.

Pew Research Center. (2017). Facts on U.S. immigrants, 2015: Statistical portrait of the foreign-born population in the U.S. Retrieved from http://www.pewhispanic.org/2017/05/ 03/facts-on-u-s-immigrants-current-data/.

Piquero, A. R. (2008). Disproportionate minority contact. The Future of Children, 18(2), 59-79.

Pogarsky, G., Lizotte, A. J., \& Thornberry, T. P. (2003). The delinquency of children born to young mothers: Results from the Rochester youth development study. Criminology, 41(4), 1249-1286. doi:10.1111/j.1745-9125.2003.tb01019.x

Puzzanchera, C., \& Robson, C. (2014). Delinquency cases in juvenile court, 2010. Office of Juvenile Justice and Delinquency Prevention, Office of Justice Programs, U.S. Department of Justice, Washington, DC.

Rheingold, A. A., Zinzow, H., Hawkins, A., Saunders, B. E., \& Kilpatrick, D. G. (2011). Prevalence and mental health outcomes of homicide survivors in a representative US sample of adolescents: Data from the 2005 National Survey of Adolescents. Journal of Child Psychology and Psychiatry, 53(6), 687-694. doi:10.1111/j.1469-7610.2011.02491.x

Ryan, J. P., Herz, D., Hernandez, P., \& Marshall, J. (2007). Child maltreatment and juvenile delinquency: Investigating child welfare bias in juvenile justice processing. Children and Youth Services Review, 27(3), 227-249.

Sickmund, M., \& Puzzanchera, C. (2015). Juvenile offenders and victims: 2014 national report. Pittsburgh PA: National Center for Juvenile Justice.

The Annie E. Casey Foundation (2014). Noncitizen youth in the juvenile justice system: $A$ guide to juvenile detention reform. Juvenile Detention Alternative Initiative, The Annie $\mathrm{E}$. Casey Foundation, Baltimore, MD.

The National Child Traumatic Stress Network (2016). Types of traumatic stress. UCLA, Los Angeles, CA.

The Pell Institute. (2017). Indicators of higher education equity in the United States: 2016 historical trend report. The Pell Institute for the Study of Opportunity in Higher Education, The University of Pennsylvania, Philadelphia, PA.

The Sentencing Project. (2016). Racial disparities in youth commitments and arrests. Washington, DC: The Sentencing Project.

Trulson, C. R., Haerle, D. R., DeLisi, M., \& Marquart, J. W. (2011). Blended sentencing, early release, and recidivism of violent institutionalized delinquents. The Prison Journal, 91(3), 255-278.

U.S. Department of Health and Human Services (2001). Youth violence: A report of the surgeon general. U.S. Government Printing Office, Washington, DC.

U.S. Department of Health and Human Services. (2014). Information on poverty and income statistics: A summary of current 2013 current population survey data. U.S. Government Printing Office, Washington, DC.

Vazsonyi, A. T., \& Chen, P. (2010). Entry risk into the juvenile justice system: African American, American Indian, Asian American, European American, and Hispanic children and adolescents. Journal of Child Psychology and Psychiatry, 51(6), 668-678. doi: 10.1111/j.1469-7610.2010.02231.x

Yun, I., Ball, J. D., \& Lim, H. (2011). Disentangling the relationship between child maltreatment and violent delinquency: Using a nationally representative sample. Journal of Interpersonal Violence, 26(1), 88-110.

Zimrow, H. M., Ruggiero, K. J., Resnick, H., Hanson, R., Smith, D., Saunders, B., \& Kilpatrick, D. (2009). Prevalence and mental health correlates of witnessed parental and community violence in a national sample of adolescents. Journal of Child Psychology and Psychiatry, 50(4), 441-450. doi:10.1111/j.1469-7610.2008.02004.x 
Copyright of Journal of Ethnicity in Criminal Justice is the property of Taylor \& Francis Ltd and its content may not be copied or emailed to multiple sites or posted to a listserv without the copyright holder's express written permission. However, users may print, download, or email articles for individual use. 